\title{
Qualification of Atomic Absorption Spectrometer in Prospective View of Pharmaceutical Analysis
}

\author{
Mahmood Ahmed1 ${ }^{*}$, Muhammad Abdul Qadir'1, Malik Qaiser Hussain ${ }^{2}$ \\ ${ }^{1}$ Institute of Chemistry, University of the Punjab, Lahore, Pakistan \\ ${ }^{2}$ Pharma Services, Lahore, Pakistan \\ Email: "
}

Received 14 May 2014; revised 25 June 2014; accepted 10 July 2014

Copyright (C 2014 by authors and Scientific Research Publishing Inc.

This work is licensed under the Creative Commons Attribution International License (CC BY). http://creativecommons.org/licenses/by/4.0/

(c) (i) Open Access

\begin{abstract}
AAS was qualified as per pharmacopoeia requirements. Copper, manganese, mercury and cadmium hallow cathode lamps were used for qualification purposes. Design qualification and installation qualification met the criteria of user requirements. Wavelength accuracy and reproducibility, resolution and baseline stability are in compliance with user requirements. Characteristics concentration or sensitivity, detection limit and characteristics mass were performed as a part of operational qualification which is $0.062 \mu \mathrm{g} / \mathrm{mL}, 0.00354 \mu \mathrm{g} / \mathrm{mL}, 1.41 \mathrm{pg}$ respectively. Results of \% RSD for precision study is 0.352 and 0.487 for flame and graphite furnace mode respectively fulfilled criteria of qualification. Performance qualification results of 20 consecutive days demonstrate the predetermined specification. Analytical instrument qualification and method validation relationship is also described by assay performed on haemodialysis concentrate. Good precision $(<2 \%)$ and accuracy $(95 \%-105 \%)$, coefficient of determination $\left(R^{2}\right)$ greater than 0.9997 for potassium, magnesium and calcium linear curves, lower detection limits for all three ingredients and robust assay data as a part of validation studies conform the qualified AAS for its intended application.
\end{abstract}

\section{Keywords}

AAS, Qualification, Pharmaceuticals, Validation

\section{Introduction}

Analytical instrument qualification (AIQ) is getting reliable and valid data from it for its intended application.

"Corresponding author.

How to cite this paper: Ahmed, M., Qadir, M.A. and Hussain, M.Q. (2014) Qualification of Atomic Absorption Spectrometer in Prospective View of Pharmaceutical Analysis. American Journal of Analytical Chemistry, 5, 674-680.

http://dx.doi.org/10.4236/ajac.2014.510075 
AIQ is important in generating the quality data for analytical method validation and provides the contribution towards the quality analysis. AIQ involves the four discrete steps of qualification such as design qualification (DQ), installation qualification (IQ), operational qualification (OQ) and performance qualification (PQ). Atomic absorption spectrometer (AAS) is among the group C instruments where conformance is complex; highly method specific and the conformity bounds are determined by their application and full qualification process applies [1]. DQ is a documented activity for necessary functions and performance specifications (technical and environmental safety) of an analytical instrument for its intended applications as well to meet user requirement which is followed by conscious decision of technical management. IQ ensured analytical instrument performance testing that is installed in suitable environment like temperature, humidity, dust and vibration levels with sufficient space for placing auxiliary gadgets as per recommendation of manufacturer. OQ is a performance verification of analytical instrument according to its overall intended anticipated operating ranges. PQ is a documented verification that analytical instrument consistently performed and gave reproducible results for a prolong period [2]. Qualification and validation always run side by side because former is an act of planning to carry out and recording tests on equipment while the latter is an act of documentation of acquired results while to check the performance of equipment in series of tests is system suitability checking [3]-[5]. Analytical instrument must be qualified first for verification of system suitability and validation of analytical method. AIQ is not a onetime event; it starts from definition until retirement of instrument. If the analytical instrument is not qualified, it will not work well for its intended application [6]. The qualified instrument performs as per set criteria throughout the whole operational life [7]. The qualification of atomic absorption spectrometer (AAS) is prime important for electrolyte determination in various formulation of haemodialysis solutions and water for diluting the concentrated haemodialysis solutions. AAS also is used for heavy and trace metals estimation in active pharmaceutical ingredients (API) for production of best quality end-user products as a part of limit tests in pharmacopoeial monographs [8]-[10]. The objective of this paper is to qualify AAS from PG-Instruments, UK as a part of good analytical laboratory practice. This document links the user requirements, functional specifications, design specification (DQ) and testing specification (IQ, OQ, PQ) per the V-model presented in Figure 1.

\section{Experimental}

\subsection{Reagent and Accessories}

Standard solution of copper, cadmium, potassium, calcium, magnesium $(1000 \mu \mathrm{g} / \mathrm{mL})$ and nitric acid (AR grade) were purchased from Thermo Scientific, UK. Hallow cathode lamps of copper, manganese, mercury, potassium, calcium, magnesium and cadmium were parts of AAS as purchased from PG-Instruments, UK. Grade 1 quality water $(0.01 \mu \mathrm{S} / \mathrm{cm})$ was prepared in our own laboratory [11].

\subsection{Qualification Steps}

\subsubsection{Design Qualification}

AAS unit with graphite furnace, compressor, chiller and eight turrets hallow cathode lamps (HCL) with deuterium background correction with bandwidth $0.2-1.0 \mathrm{~nm}$ and computerized automatic control over the main unit were the user requirements. These mentioned requirements which are easy to assemble, dismantle and cleaning approach to various components like hallow cathode lamps and graphite furnace.

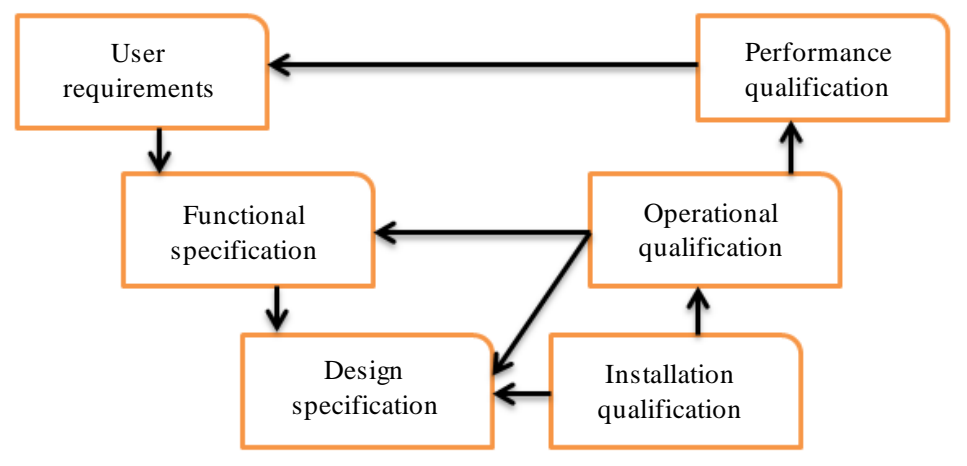

Figure 1. Tracebility and linkage. 


\subsubsection{Installation Qualification}

Verification of software and hard ware products like compatibility of AAWin ${ }^{\circledR}$ (data station) for data processing and HCL, pressure control regulators for acetylene gas, argon gas and air respectively as defined in the functional requirements were documented. Electrical, mechanical and environmental specifications were also assured.

\subsubsection{Operational Qualification}

The operational functions of AAS such as wavelength accuracy and reproducibility, resolution, baseline stability, characteristics concentration or sensitivity, detection limit, characteristics mass and precision were determined and demonstrated the functions as expected. The parameters for all these operational functions are presented in Table 1.

Wavelength correction was carried out by using the mercury (Hg) lamp with $0.2 \mathrm{~nm}$ bandwidth and records the peaks at $253.7 \mathrm{~nm}, 546.1 \mathrm{~nm}, 871.6 \mathrm{~nm}$. The average value was calculated by using the relationship $\bar{\lambda}=1 / n \sum \lambda_{i}$, where $\bar{\lambda}$ is average value, $\lambda_{i}$ is measured value. The difference between the average value $\bar{\lambda}$ and the standard is the wavelength accuracy. The difference between the maximum value and minimum value is the wavelength reproducibility. All the measurements were made triplicate. For the resolution studies at $0.2 \mathrm{~nm}$ bandwidth manganese HCL having $2 \mathrm{~mA}$ current was used and ratio of maxima and minima of recorded peaks was calculated. The instrument was run with a copper lamp installed, for thirty minutes at $0.2 \mathrm{~nm}$ bandwidth and set lamp current to $3 \mathrm{~mA}$ after searching the peak at $324.7 \mathrm{~nm}$ by flame working mode. Set the display range \pm 0.006 absorption units. The baseline stability was calculated by average difference between maximum and minimum absorption value. Adjusted the bandwidth at $0.4 \mathrm{~nm}$ using copper HCL and the parameters to conditions presented in Table 1 then alternately measure the copper standard solution $(0.5 \mu \mathrm{g} / \mathrm{mL})$ and blank solution ( $0.5 \%$ nitric acid). Calculate the characteristics concentration by using the formula: $\mathrm{Cc}=0.0044 \times \mathrm{C} / \mathrm{A}$, where $\mathrm{C}$ is concentration of standard solution and A is average absorbance $(n=5)$. Adjusted the parameters to optimum conditions using copper HCL and set the absorbance display to four decimal places with integration time of 3 sec with continuously measured the blank solution ( $0.5 \%$ nitric acid) 20 times. Calculated the detection limit by using the relationship $3 \times$ SD, where SD is standard deviation of blank. Programmed the graphite furnace heating process and injected the $20 \mu \mathrm{L}$ standard solution of cadmium $(0.1 \mu \mathrm{g} / \mathrm{mL})$ by using the cadmium HCL and characteristics mass was calculated by formula: $\mathrm{Qc}=\mathrm{C} \times \mathrm{H} \times 0.0044 / \mathrm{A}$, where $\mathrm{C}$ is concentration in $\mathrm{g} / \mathrm{L}, \mathrm{H}$ is volume of sample in litres and A is absorbance. Precision of flame and graphite mode was evaluated by using the $2.0 \mu \mathrm{g} / \mathrm{mL}$ and $0.1 \mu \mathrm{g} / \mathrm{mL}$ copper standard solutions respectively. Continuously measured the standard solution and blank for 11 times alternatively for both the modes. The precision is presented in \% RSD.

\subsubsection{Performance Qualification}

The parameters for evaluation of performance qualification was same as that of operational qualification by running the system for 20 consecutive working days, all relevant information and data was recorded.

Table 1. Parameters for operational functions.

\begin{tabular}{|c|c|c|c|c|c|c|c|}
\hline Parameters & $\begin{array}{l}\text { Wavelength accuracy } \\
\text { and reproducibility }\end{array}$ & Resolution & $\begin{array}{l}\text { Baseline } \\
\text { stability }\end{array}$ & $\begin{array}{l}\text { Characteristics } \\
\text { concentration or sensitivity }\end{array}$ & $\begin{array}{l}\text { Detection } \\
\text { limit }\end{array}$ & $\begin{array}{l}\text { Characteristics } \\
\text { mass (GF) }\end{array}$ & Precision \\
\hline HCL & Mercury & Manganese & Copper & Copper & Copper & Cadmium & Copper \\
\hline $\begin{array}{l}\text { Lamp current } \\
\text { (mA) }\end{array}$ & 3.0 & 2.0 & 3.0 & 5.0 & 5.0 & 5.0 & 5.0 \\
\hline $\begin{array}{l}\text { Bandwidth } \\
\text { (nm) }\end{array}$ & 0.2 & 0.2 & 0.2 & 0.4 & 0.4 & 0.4 & 0.4 \\
\hline $\begin{array}{l}\text { Negative voltage } \\
\text { (volt) }\end{array}$ & 300 & 300 & 300 & 300 & 300 & 300 & 300 \\
\hline $\begin{array}{c}\text { Gas flow (acetylene) } \\
\text { (mL/min) }\end{array}$ & 1200 & 1700 & 2000 & 2000 & 2000 & - & 2000 \\
\hline $\begin{array}{l}\text { Flame height } \\
(\mathrm{mm})\end{array}$ & 6.0 & 6.0 & 6.0 & 6.0 & 6.0 & - & 6.0 \\
\hline $\begin{array}{l}\text { Flame position } \\
\quad(\mathrm{mm})\end{array}$ & 0.0 & 0.0 & 0.0 & 0.0 & 0.0 & - & 0.0 \\
\hline
\end{tabular}

GF: Graphite Furnace. 


\subsubsection{Equipment Qualification and Method Validation Relationship}

AIQ and method validation are interlinked with each other, tested and defined specification as part of qualification confirmed that system is suitable for validation of a method. For the purpose of method validation system suitability tests is performed on quality control samples and compare its results with known values [12]-[15]. In the present work system suitability test is performed for the analysis and validation of analytical method for haemodialysis concentrates. Three standards each of potassium (1.6, 2.0, $2.4 \mu \mathrm{g} / \mathrm{mL})$, magnesium $(0.50,0.75$, $1.00 \mu \mathrm{g} / \mathrm{mL}$ ) and calcium $(0.60,1.25,2.0 \mu \mathrm{g} / \mathrm{mL}$ ) were taken to check the suitability of AAS (previously qualified) for analysis of haemodialysis concentrate. Specificity, precision, linearity, accuracy and robustness were performed on account of method validation.

\subsubsection{Site for AAS Qualification}

These qualification steps were performed at the site of Renacon Pharma (Pvt.) Limited, Lahore, Pakistan.

\section{Results and Discussion}

Technical specification like wavelength range (190 - $900 \mathrm{~nm}$ ), deuterium background correction, bandwidth 0.2 - $1.0 \mathrm{~nm}$ with automatic scanning mode, data processing of measurement and read out mode of package unit and components were assured from manual provided by manufacturer. AAS in analytical laboratory with all accessories such as oil free compressor, reducing valves for argon, acetylene gases and chiller for graphite furnace were checked which are well fitted as part of user requirement specification and site acceptance test. These parameters gave assurance to DQ. As a part of IQ, environmental conditions were assured, AAS was installed in laboratory where temperature $\left(<25^{\circ} \mathrm{C}\right)$ and humidity $(<50 \%)$ are well maintained, away from electromagnetic field, strong radiation, strong light, solvent vapors and chemical treatment room then configured the computer and connected peripheral devices. Verified the software data processing such as measurement in absorbance, concentration, transmittance, emission intensity and read out in continuous, peak height, peak area mode which is functional requirements. Data processing functions like multi-standard calibration method, standard addition method, interpolation method, integration time: 0.1 - $20 \mathrm{sec}$, sampling delay: 0 - $20 \mathrm{sec}$, no of standard samples 1 - 8, no of samples 0 - 100, slope, mean value, standard deviation (SD), relative standard deviation (RSD), correction coefficient, concentration value were also verified. Analytical results, instrumental and measurement parameters, signal profile and calibration curves all were stored in the computer hard disk confirmed the data storage functions. Wavelength accuracy was evaluated on three different wavelengths of mercury, the scanned peak in triplicate and standard wavelength are presented in Table 2, the difference between standard and obtained are in compliance with user requirement limit which is $\pm 0.25 \mathrm{~nm}$.

Wavelength reproducibility was performed at the interval of 6 hrs maximum and minimum value were reported, the difference between upper and lower value within the acceptance criteria. Resolution was reported by searching the peak at $279.5 \mathrm{~nm}$ using manganese HCL, three peaks were obtained at 279.46, 279.78 and 280.10 $\mathrm{nm}$. The ratio of the valley energy values at first two peaks is $0.191(\mathrm{n}=3)$ which is less than 0.30 as recommended by manufacturer. The resolution data is summarized in Table 3 .

Baseline stability was performed by running the blank solution (0.5\%) using copper HCL at $324.7 \mathrm{~nm}$ and recorded the maximum and minimum absorption values at interval of $10 \mathrm{sec}$, reported the 30 consecutive readings. The difference between the average upper and lower values is 0.0017 which is in accordance with operation requirement less than 0.005 as manufacturer recommendation. The baseline stability is presented in Figure 2.

The characteristics concentration was found to be $0.062 \mu \mathrm{g} / \mathrm{mL}$ which is obtained by using the copper standard solution $(0.5 \mu \mathrm{g} / \mathrm{mL})$ and blank solution absorption measurement alternatively. The detection limit of AAS was measured by running the blank solution and absorption was measured in triplicate with $3 \mathrm{sec}$ integration time and SD of 20 consecutive readings was calculated which is found to be 0.00118 and detection limit is $0.00354 \mu \mathrm{g} / \mathrm{mL}$. The characteristics mass which is specific for graphite furnace mode of AAS measurement was found to be $1.41 \mathrm{pg}$ after injecting $20 \mu \mathrm{L}$ cadmium standard solution $(0.1 \mu \mathrm{g} / \mathrm{mL})$ while the user limit is $5.0 \mathrm{pg}$. The precision of AAS in both flame and graphite furnace mode was obtained by using copper and cadmium standard solution respectively and reported in \% RSD. The \% RSD is 0.532 for flame mode and 0.487 graphite mode. The results of characteristics concentration, detection limit, characteristics mass and precision data is reported in Table 4. 
Table 2. Wavelength accuracy and reproducibility.

\begin{tabular}{|c|c|c|c|}
\hline \multicolumn{4}{|c|}{ Wavelength accuracy } \\
\hline Standard wavelength (nm) & \multicolumn{2}{|c|}{ Wavelength obtained $(\mathrm{n}=3)$} & Difference \\
\hline 253.700 & \multicolumn{2}{|c|}{253.683} & -0.017 \\
\hline 546.100 & \multicolumn{2}{|c|}{546.003} & -0.097 \\
\hline 871.600 & \multicolumn{2}{|c|}{871.630} & +0.030 \\
\hline \multicolumn{4}{|c|}{ Wavelength reproducibility } \\
\hline \multicolumn{4}{|c|}{ Time interval (6 hr) } \\
\hline & Maximum & Minimum & Difference \\
\hline 253.700 & 253.690 & 253.680 & 0.01 \\
\hline 546.100 & 546.010 & 546.00 & 0.01 \\
\hline 871.600 & 871.630 & 871.630 & 0.00 \\
\hline
\end{tabular}

Table 3. Resolution studies.

\begin{tabular}{ccc}
\hline Standard value $(\mathrm{nm})$ & Peaks obtained $(\mathrm{nm})$ & Valley energy values ratio \\
\hline 279.5 & $279.46,279.78,280.10$ & $14.9 / 78.2=0.190$ \\
279.5 & $279.46,279.79,280.12$ & $15.0 / 78.0=0.192$ \\
279.5 & $279.47,279.75,280.08$ & $15.0 / 78.0=0.192$ \\
& & 0.191 \\
\hline
\end{tabular}

Table 4. Characteristics concentration, detection limit, characteristics mass and precision data.

\begin{tabular}{cccc}
\hline $\begin{array}{c}\text { Characteristics concentration } \\
(\mu \mathrm{g} / \mathrm{mL})\end{array}$ & $\begin{array}{c}\text { Detection limit } \\
(\mu \mathrm{g} / \mathrm{mL})\end{array}$ & $\begin{array}{c}\text { Characteristics mass } \\
\text { pg }\end{array}$ & $\begin{array}{c}\text { Precision } \\
\% \text { RSD }\end{array}$ \\
\hline 0.062 & 0.00354 & 1.41 & 0.532 (flame), 0.487 (graphite furnace) \\
\hline
\end{tabular}

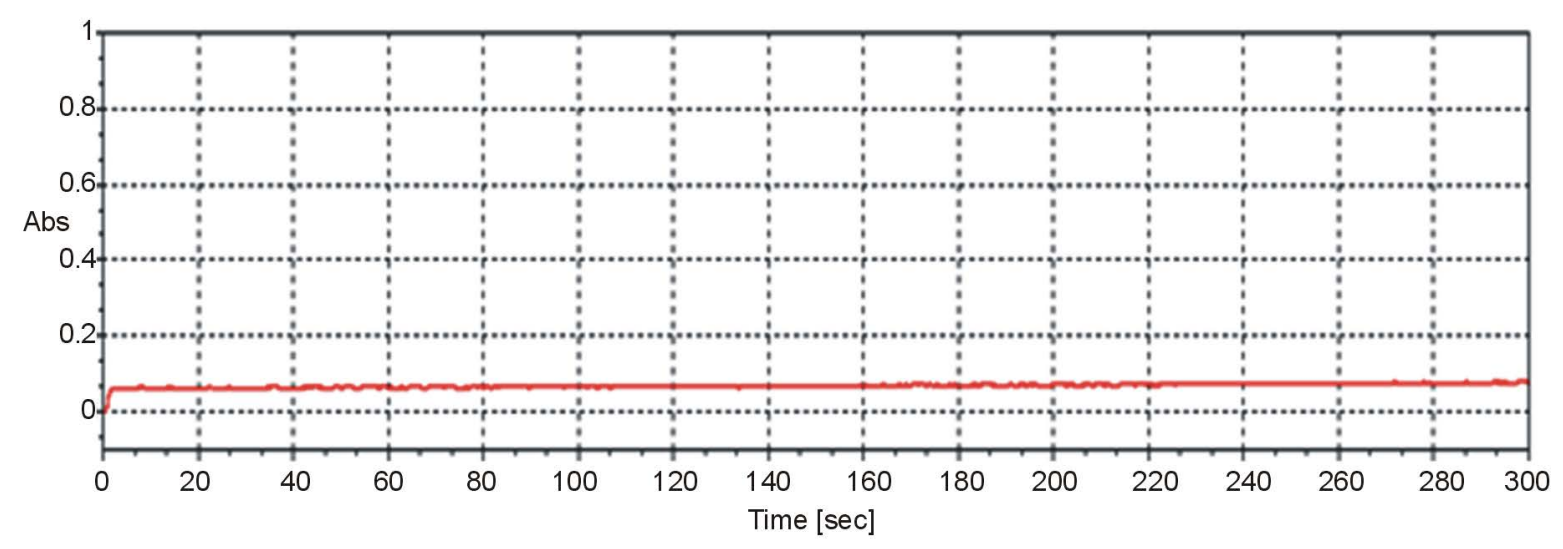

Figure 2. Baseline stability.

All these parameters were performed as the part of OQ. PQ parameters were same as that of OQ but the AAS was run for consecutive 20 days, PQ results demonstrated that performance consistently meets pre-determined specifications. The PQ results average of 20 days are summarized in Table 5.

For purpose of system suitability each standard of potassium, magnesium and calcium was run in triplicate and results are summarized in Table 6. \% RSD values for all the standards less than 2 which are in compliance with standard requirements. 
$766.5 \mathrm{~nm}, 422.7 \mathrm{~nm}$ and $285.2 \mathrm{~nm}$ absorption lines were selected for specificity studies; at these selected lines no spectral interference was observed. Repeatability and intermediate precision was performed on same and three consecutive days respectively. Six replications of each of standard (potassium: $2.00 \mu \mathrm{g} / \mathrm{mL}$, magnesium: $0.75 \mu \mathrm{g} / \mathrm{mL}$, calcium: $1.25 \mu \mathrm{g} / \mathrm{mL}$ ) that is 100 percent of target concentration was performed low value of \% RSD conforms the method precision. Precision results are reported in Table 7.

A six point calibration curve was drawn which covers the $80 \%-120 \%$ of target concentration in sample and linear regression equation was applied for limit of detection and limit of quantitation using the formula (LOD = $\mathrm{yB}+3 \mathrm{sB} ; \mathrm{LOQ}=\mathrm{yB}+10 \mathrm{sB})$ respectively. Coefficient of determination $\left(\mathrm{R}^{2}\right)$ for three standards curves is greater than 0.9997. Parameters of linear regression equation, LOD and LOQ are presented in Table 8.

Accuracy is reported in terms of \% recovery studies, sample of haemodialysis concentrate was spiked with known concentration of standard solution of each content at low $(0.10 \mu \mathrm{g} / \mathrm{mL})$, medium $(0.15 \mu \mathrm{g} / \mathrm{mL})$ and high $(0.20 \mu \mathrm{g} / \mathrm{mL})$ levels and all the measurements are performed in triplicates. The results of recovery studies are in between $95 \%$ - 105\% which in compliance with ICH guidelines. The recovery data is reported in Table 9 .

Purposeful changes in measuring parameters like integration time $(0.3 \mathrm{sec}-0.2 \mathrm{sec})$, bandwidth $(0.4 \mathrm{~nm}-0.2$ $\mathrm{nm})$ and flame height $(6.0 \mathrm{~mm}-5.0 \mathrm{~mm})$ was made for robustness and assay was performed. Robust data of performed assay (\% mean \pm SD) is reported in Table 10 .

Table 5. PQ results.

Wavelength accuracy and reproducibility

$$
\text { Resolution }
$$

Baseline stability

Characteristics concentration or sensitivity

Detection limit

Characteristics mass (GF)

Precision
$<0.025 \mathrm{~nm}$
0.197
0.0017
0.061
0.00352
1.42

0.534 (flame), 0.489 (graphite furnace)

Table 6. System suitability tests.

\begin{tabular}{cccccccccc}
\hline Concentration & \multicolumn{3}{c}{ Potassium $(\mathrm{n}=3)$} & \multicolumn{3}{c}{ Magnesium $(\mathrm{n}=3)$} & \multicolumn{3}{c}{ Calcium $(\mathrm{n}=3)$} \\
\hline$\mu \mathrm{g} / \mathrm{mL}$ & Std. 1 & Std. 2 & Std. 3 & Std. 1 & Std. 2 & Std. 3 & Std. 1 & Std. 2 & Std. 3 \\
Theoretical & 1.60 & 2.00 & 2.40 & 0.50 & 0.75 & 1.00 & 0.60 & 1.25 & 2.00 \\
Measured & 1.61 & 1.99 & 2.41 & 0.51 & 0.76 & 0.99 & 0.59 & 1.24 & 2.01 \\
\% RSD & 0.89 & 1.02 & 0.76 & 0.63 & 0.78 & 0.91 & 1.01 & 1.02 & 0.21 \\
\hline
\end{tabular}

Table 7. Precision data.

\begin{tabular}{|c|c|c|c|c|c|c|c|c|c|}
\hline \multirow{3}{*}{$\begin{array}{l}\text { Concentration } \\
\qquad \mu \mathrm{g} / \mathrm{mL}\end{array}$} & \multicolumn{3}{|c|}{ Repeatability $(n=6)$} & \multicolumn{6}{|c|}{ Intermediate precision $(n=6)$} \\
\hline & \multirow{2}{*}{ Potassium } & \multirow{2}{*}{ Magnesium } & \multirow{2}{*}{ Calcium } & \multicolumn{3}{|c|}{ Day 1} & \multicolumn{3}{|c|}{ Day 2} \\
\hline & & & & Potassium & Magnesium & Calcium & Potassium & Magnesium & Calcium \\
\hline Theoretical & 2.00 & 0.75 & 1.25 & 2.00 & 0.75 & 1.25 & 2.00 & 0.75 & 1.25 \\
\hline Measured & 1.99 & 0.76 & 1.26 & 2.01 & 0.74 & 1.26 & 2.02 & 0.74 & 1.26 \\
\hline$\%$ RSD & 0.63 & 0.91 & 1.01 & 0.21 & 0.54 & 0.78 & 0.23 & 0.87 & 0.91 \\
\hline
\end{tabular}

Table 8. Linear regression equations, LOD and LOQ.

\begin{tabular}{ccccc}
\hline Contents & Concentration $(\mu \mathrm{g} / \mathrm{mL})$ & Equation & $\mathrm{R}^{2}$ & $\mathrm{LOD}(\mu \mathrm{g} / \mathrm{mL})$ \\
\hline Potassium & $0.0-5.0$ & $\mathrm{y}=0.0852 \mathrm{x}+0.0068$ & 0.9998 & 0.0010 \\
Magnesium & $0.0-1.0$ & $\mathrm{y}=0.1478 \mathrm{x}+0.0019$ & 0.9998 & 0.0018 \\
Calcium & $0.0-2.5$ & $\mathrm{y}=0.0232 \mathrm{x}+0.0063$ & 0.9998 & 0.0042 \\
\hline
\end{tabular}


Table 9. Recovery studies.

\begin{tabular}{|c|c|c|c|}
\hline \multirow{2}{*}{ Spike level } & Potassium \% & Magnesium \% & Calcium \% \\
\hline & Mean \pm SD & Mean \pm SD & Mean \pm SD \\
\hline Low & $99.09 \pm 0.32$ & $99.69 \pm 0.12$ & $99.19 \pm 0.02$ \\
\hline Medium & $98.12 \pm 0.11$ & $100.19 \pm 0.41$ & $99.72 \pm 0.91$ \\
\hline High & $101.01 \pm 0.34$ & $99.01 \pm 0.44$ & $100.01 \pm 0.94$ \\
\hline
\end{tabular}

Table 10. Robustness data.

\begin{tabular}{ccr}
\hline & \% Assay mean \pm SD & Calcium \\
Potassium & Magnesium & $99.78 \pm 0.56$ \\
$100.01 \pm 0.09$ & $99.83 \pm 0.12$ & 99.78 \\
\hline
\end{tabular}

\section{Conclusion}

PG-990 AAS of PG-Instruments, UK was qualified for its intended applications in pharmaceutical industry. Attaining the correct results, rapid identification and rectification of measurement related problems are well handled by qualified instrument. Qualification also provided the ground to develop and validate new analytical methods.

\section{References}

[1] USP 36 (2013) <1058> Analytical Instrument Qualification. General Information. https://hmc.usp.org/sites/default/files/documents/HMC/GCs-Pdfs/c1058\%20USP36.pdf

[2] WHO (2010) WHO Good Practices for Pharmaceutical Quality Control Laboratories. WHO, Geneva.

[3] Ermer, J. and Miller, J.H.M. (2005) Method Validation in Pharmaceutical Analysis. Wiley-VCH Verlag GmbH \& Co. KGaA, Weinheim.

[4] Zacarias, M.I. (2010) Verification and Maintenance of Analytical Instruments According to ISO/IEC 17025 Standard. University of Barcelona, Barcelona.

[5] Imtiaz, H.S. (2006) Validation Standard Operating Procedures: A Step-by-Step Guide for Achieving Compliance in the Pharmaceutical, Medical Device, and Biotech Industries. CRC Press Taylor \& Francis Group, UK.

[6] Ludwig, H. (2009) Analytical Instrument Qualification and System Validation. Agilent Technologies, Santa Clara.

[7] Barron, J.J. and Colin, A. (2006) Equipment Qualification and Its Application to Conductivity Measuring Systems. Accreditation and Quality Assurance, 11, 554-561. http://dx.doi.org/10.1007/s00769-006-0178-9

[8] Ph Eur Monograph 0128 (2013) Solutions for Haemodialysis.

[9] Ph Eur Monograph 1167 (2013) Haemodialysis Solutions, Concentrated, Water for Diluting.

[10] Ph Eur (2013) Appendix VII Limit Tests.

[11] Jeffery, G.H., Bassett, J., Mendham, J. and Denney, R.C. (1989) Vogel’s Textbook of Quantitative Chemical Analysis. John Wiley and Sons, New York.

[12] AOAC (2007) How to Meet ISO 17025 Requirements for Methods Verification.

[13] US FDA (2000) Guidance for Industry: Analytical Procedures and Methods Validation: Chemistry, Manufacturing, and Controls and Documentation.

[14] ICH (1995) Validation of Analytical Procedures: Definitions and Terminology.

[15] ICH (1996) Validation of Analytical Procedures: Methodology. Guidance for Industry. 
Scientific Research Publishing (SCIRP) is one of the largest Open Access journal publishers. It is currently publishing more than 200 open access, online, peer-reviewed journals covering a wide range of academic disciplines. SCIRP serves the worldwide academic communities and contributes to the progress and application of science with its publication.

Other selected journals from SCIRP are listed as below. Submit your manuscript to us via either submit@scirp.org or Online Submission Portal.
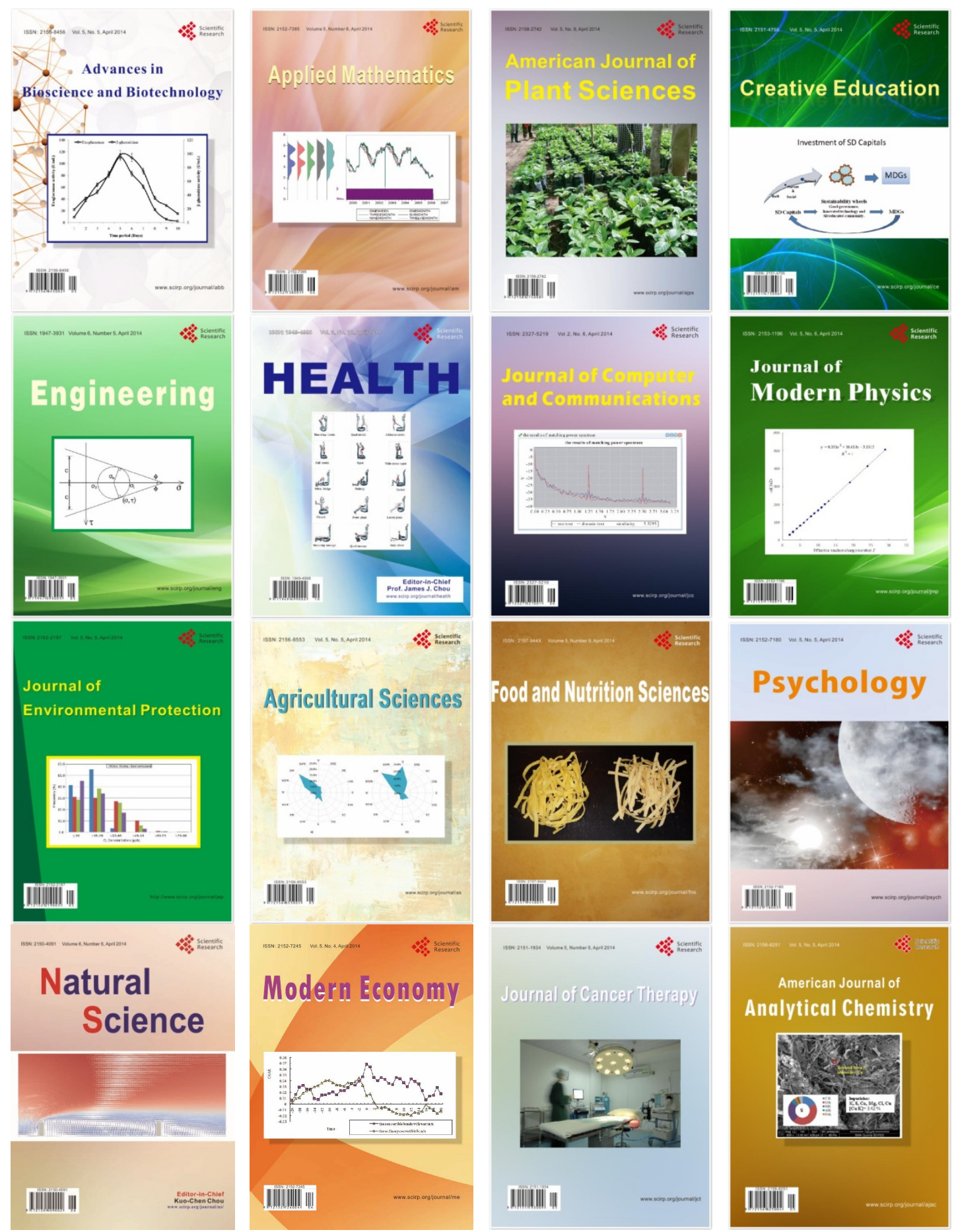